\title{
Debates acerca de la antropología del Estado y las políticas públicas en contextos latinoamericanos contemporáneos
}

\author{
Liliana Raggio, ${ }^{1}$ Kátia Sento Sé Mello² \\ y Juan Pablo Matta ${ }^{3}$ \\ ${ }^{1}$ Universidad de Buenos Aires, Argentina \\ Correo electrónico: lily.raggio@gmail.com \\ ${ }^{2}$ Universidade Federal do Rio de Janeiro, Brasil \\ Correo electrónico: ksemello@gmail.com \\ 3 Universidad Nacional del Centro de la Provincia de Buenos Aires, Argentina \\ Correo electrónico: juanpablomatta@gmail.com
}

Cuando este dossier sea publicado ya habremos transcurrido al menos nueve meses de este año 2020, en el cual el mundo se encontró inmerso en la peor pandemia conocida desde la llamada gripe española en los albores del siglo pasado. Y si bien los artículos que lo componen fueron escritos antes, en todos ellos la relación entre el Estado y los distintos sujetos y colectivos de la sociedad civil aparecen iluminados por el foco de la perspectiva antropológica. La interpretación de las distintas expresiones que dan cuenta de cómo se modelan las condiciones de acceso a la ciudadanía y las disputas que conllevan la concreción de mayores igualdades de clase, de género, étnicas, religiosas, en fin, de la multiplicidad de dimensiones socioculturales que configuran los contextos de los trabajos aquí reunidos, revelaron el potencial analítico que esta perspectiva reviste.

Situados en este singular momento histórico, quienes coordinamos esta edición no podemos dejar de observar el rol de los distintos Estados que componen la región, respecto del engañoso dilema planteado entre la economía y la salud en las políticas públicas llevadas adelante en función de privilegiar una u otra cuestión; ni dejar de subrayar los aportes de nuestra disciplina en conjunto con otras ciencias sociales, en la comprensión de las experiencias cotidianas de las diversas poblaciones y su transformación en tanto insumo para la formulación de políticas en el acuciante presente, pero sobre todo en el futuro, vislumbrado también como oportunidad de mayor igualdad en la región.

La aproximación de la antropología a estas temáticas obedece a una larga lista de razones encabezadas por $\mathrm{y}$, a la vez, articuladas con la redefinición del objeto de estudio de una disciplina que en su surgimiento se ocupó del conocimiento de las sociedades "no occidentales". 
En palabras de Cris Shore:

Corriendo el riesgo de simplificar, hay dos razones clave que explican por qué las políticas públicas se han convertido en un foco tan importante de interés antropológico. La primera es el rol dominante que tienen las políticas a la hora de regular y organizar las sociedades contemporáneas, a la hora de dar forma a las identidades de las personas y en cuanto a su sentido sobre sí mismas. Las políticas están profundamente implicadas en la manera como nos construimos como individuos y como sujetos. (Shore, 2010, p. 36)

El presente dossier reúne una serie trabajos provenientes de distintas geografías que focalizan en diferentes aspectos del Estado y la estatalidad desde una perspectiva antropológica. En mucho de ellos, además, se presentan interesantes discusiones a propósito del papel de las/os antropólogas/os en el Estado y sobre las complejidades que supone este singular contexto para el desarrollo del trabajo etnográfico. La diversidad de perspectivas reunida aquí posibilitan un diálogo teórico anclado no solo en un leguaje disciplinar común, sino además en una coyuntura latinoamericana compartida.

Dos de los artículos problematizan las políticas de seguridad de los Estados e incorporan el decurso histórico y a partir de ahí develan las complejas relaciones que se establecen entre la multiplicidad de actores que intervienen en dicho campo. Horacio Sabarots realiza un recorrido histórico y teórico de las relaciones entre las políticas públicas en seguridad y nuestra disciplina, considerando diversos abordajes. Para hacerlo, arranca desde un momento fundacional en el cual, con la vuelta de la democracia en la Argentina, la antropología adquiere una presencia pública inédita gracias a los trabajos del Equipo Argentino de Antropología Forense, hasta los debates en torno de la seguridad-inseguridad con una dimensión fuertemente invocada en democracia: la participación comunitaria. Tomando en consideración tanto las miradas de autores extranjeros como las investigaciones realizadas por el Equipo de Antropología Política y Jurídica del Instituto de Ciencias Antropológicas de la Facultad de Filosofía y Letras de la Universidad de Buenos Aires, aporta con sus propias investigaciones elementos indispensables a tener en cuenta para "sostener e incrementar las investigaciones y las vinculaciones de la academia con la gestión pública [...] en momentos políticos donde la vulnerabilidad, la precariedad, el racismo, la discriminación y la violencia institucional encuentran terreno fértil". (pp. 28, en este volumen)

Por su parte, Marcelli Cipriani y Rodrigo Ghiringhelli de Azevedo analizan la transición entre dos momentos que caracterizan las tensas relaciones entre grupos de personas privadas de libertad y la administración penitenciaria en la Cárcel Pública de la ciudad de Porto Alegre en Rio Grande do Sul, en Brasil. El primer momento se definió entre los años 1980 y 1990, cuando la principal cárcel de la ciudad fue escenario de fugas, homicidios y rebeliones, y la policía militar pasó a liderar la gestión penitenciaria. Desde la década de 2000 -a pesar del encarcelamiento masivo y del hacinamiento de las cárceles en general, y de la cárcel pública en particular-, tales rebeliones e inestabilidades se han convertido en eventos ocasionales según los autores, quienes argumentan además que ha habido un cierto "acomodo" de los antagonismos entre las personas privadas de libertad y la policía que dirige la prisión. Añaden que ese "equilibrio precario" de fuerzas se logró principalmente mediante el intercambio de concesiones entre estos actores sociales. 
La introducción de la perspectiva de género en el análisis antropológico, que ha cobrado una creciente relevancia en los últimos años, está presente en otros dos trabajos: Diana Bento de Mello y Alejandra Vázquez analizan comparativamente la ausencia de una problematización respecto de las cuestiones de género en las políticas culturales. Toman el caso del Programa Nacional de Coros y Orquestas Infantiles y Juveniles del Bicentenario en Buenos Aires y el Samba en tanto movimiento cultural contemporáneo de artistas, trabajadorxs de la cultura y gestores culturales de Río de Janeiro. En su artículo proponen abordar la intersección entre género y cultura como parte de dinámicas transversales a nuestra región latinoamericana para dar cuenta de las deudas que quedan en pie. Aun cuando en las décadas precedentes se realizaron avances significativos a partir del paradigma de ampliación de derechos con foco en la diversidad, en palabras de las autoras, "se sigue reproduciendo esta división ancestral del ámbito privado-femenino y ámbito público-masculino, que orienta roles de género que se construyen a partir de normas y prescripciones heteronormativas". (pp. 61, en este volumen) Plantean entonces la incorporación de la perspectiva de género en la gestión de las políticas culturales como modo de avanzar en su deconstrucción.

Desde Chile, María Catalina Álvarez Burgos nos presenta un artículo que intersecta el género y la producción pesquera. La autora centra su investigación en la lucha por el reconocimiento de las organizaciones de mujeres pescadoras poniendo de manifiesto los diferentes accionares estatales frente a lo que denomina la institucionalidad del género. Analiza la emergencia de arenas políticas donde el Estado se encuentra con las organizaciones territoriales que, constituidas en red, demandan un reconocimiento económico y simbólico de su labor. En esta dinámica, mediante la observación etnográfica de interfaces socioestatales, la autora registra las diferencias entre los distintos niveles jurisdiccionales y también aquellas que se producen en el accionar cotidiano entre los funcionarios y las organizaciones territoriales de mujeres.

En otros dos artículos se aborda el tratamiento institucional de las problemáticas referidas a la vulneración de los derechos de las infancias y adolescencias y de conflictos vecinales en agencias gubernamentales, incorporando no solo las perspectivas de quienes son sus destinatarias y destinatarios sino también de las y los antropólogos que llevan adelante esas investigaciones.

Carolina Ciordia expone algunos de los argumentos de las narrativas hegemónicas vigentes en el campo de las políticas públicas destinadas a las infancias y adolescencias respecto de dos derechos reconocidos para esos sujetos: a vivir en familia y a la participación. Su propósito es incorporar los sentidos construidos por las y los jóvenes destinatarios de esas políticas como forma de contribuir a la realización de esos derechos. Para ello se vale de la construcción de un caso paradigmático y presenta parte del testimonio de una de sus informantes producto del trabajo etnográfico que desarrolla en la actualidad. A partir de ese análisis nos propone cuestionar nociones tales como "infancia universal" o "juventud hegemónica" y comprender las distintas maneras de transitar estas etapas

Matías Rafael Pizarro y Natalia Jimena Larrea problematizan el papel de los documentos y las implicancias de los estudios de caso para etnografías desarrolladas en contextos estatales. A partir de sus propias experiencias etnográficas en dos ámbitos estatales de tramitación de conflictos vecinales y de administración de situaciones asociadas a la niñez con derechos vulnerados destacan "la manera en que diversas situaciones y conflictos eran traducidos en los documentos a 
un lenguaje que ordena, categoriza y clasifica, buscando normalizar conductas, armonizar vínculos, definir roles de parentesco y asignar identidades" (pp. (En página 122.), en este volumen); al tiempo que proponen distinguir entre estudios de casos y estudios con casos. El artículo destaca la centralidad que el Estado asume en el contexto de sus investigaciones como contexto y escenario en el que las personas discuten sus asuntos locales cotidianos.

Otro conjunto de trabajos coloca el énfasis en las diversas y mutuas interacciones que se producen entre agentes estatales y destinatarios de políticas públicas en la cotidianeidad de su implementación. En esa dirección, para reflexionar sobre la producción social de dinero en las políticas de transferencia monetarias del Estado, Martín Hornes aborda la pluralidad de significados atribuidos al "dinero del Estado". Desde la perspectiva teórica de la sociología del dinero, Hornes desarrolla un trabajo etnográfico sobre la implementación de un programa de transferencias monetarias a nivel local en el que conecta universos como el de los saberes expertos en políticas sociales con las dinámicas monetarias y familiares de los hogares destinatarios de esos programas, a la vez que destaca los intersticios y las formas de ensamblaje que existen entre los distintos significados del dinero que atraviesan un mundo de prácticas y relaciones sociales plurales. Propone que "la producción social del dinero de las TM es el resultado de un ensamblaje de significados plurales del dinero que se suceden en distintos tiempos y espacios sociales e involucran a diferentes tramas de actores que movilizan diversos saberes y producen significados" (pp. 138, en este volumen) disímiles sobre el dinero.

Por su parte, Agustina Girado problematiza el accionar de una agrupación social abocada a la generación de proyectos habitacionales en una ciudad media bonaerense (Argentina) a partir de repasar la trayectoria de vida de una de sus principales referentes, así como los inicios de la agrupación, observando las ideas de Estado que se encarnan en discursos, prácticas, relaciones y conceptos de los actores sociales con los cuales se realizó el trabajo etnográfico. Para la autora, pensar el Estado en sus múltiples presencias resulta una clave analítica central para dar cuenta de la generación de relaciones sociales y de bienes que no solo permiten desbordar el nivel local, sino también habilitar mayores grados de proximidad y vinculación con diversos funcionarios y dependencias estatales. El artículo muestra cómo las referentes barriales con las que trabajó articularon creativamente prácticas individuales y colectivas, la lucha y la tramitación, así como diferentes lógicas y lenguajes que hacen a la producción del hábitat y que se vinculan con la implementación de políticas públicas, con la organización colectiva, los partidos políticos, la Universidad y la administración estatal.

En otro contexto, Víctor Hugo Villanueva Gutiérrez analiza las estrategias de lucha del grupo autodenominado Damnificados Unidos de la Ciudad de México frente al programa para la reconstrucción propuesto por el Gobierno de la Ciudad de México, en el marco de las afectaciones en la infraestructura urbana luego del sismo ocurrido el 19 de septiembre de 2017 en el municipio de Axochiapan, Morelos. Destaca que la lucha y movilización que mantiene este grupo con el objetivo de construir lo que caracterizan como una ruta justa, digna y segura para las personas afectadas por el sismo muestra nuevos derroteros en el análisis de la problemática urbana en el contexto de un desastre y la intervención del capital global. El análisis focaliza en el lenguaje de protesta en torno a la política pública y muestra el modo en que en esta experiencia se recuperan algunos rasgos estéticos de las luchas populares de los años setenta, tanto en México como en Chile, Argentina y Brasil. 
En tanto Julieta Gaztañaga, en su análisis de las "misiones comerciales e institucionales internacionales de la Región Central" de Argentina, de las que participaron funcionarios estatales y empresarios, sostiene que los viajes al exterior, por el perfil agroexportador de las provincias y el peso de los empresarios locales, se han configurado como una política pública regional. El éxito alcanzado por estas misiones se debe a las dinámicas políticas que tiene el "federalismo" como valor fundamental, mucho más que a su contenido comercial. La autora observa en su investigación que las políticas de gobierno son parte de una misma relación dialéctica en la que existe una imposición de lo político y lo económico, así como un vínculo entre la toma de decisiones a nivel local y la forma en que interactúan los actores gubernamentales y no gubernamentales.

Y para concluir, a partir de dos trabajos se invita al debate acerca de la formación y del margen de autonomía que adquieren quienes gestionan las políticas públicas dentro del aparato estatal. En su artículo, Boris Maia analiza la formación de los agentes del servicio público fiscal en Brasil a lo largo del aprendizaje que realizan para luego ocupar puestos en una élite burocrática. La aprobación en un concurso público convierte a los sujetos ordinarios en funcionarios públicos a partir de lo que Bourdieu ha caracterizado como la "magia del Estado". Con el concepto de sometimiento burocrático e inspirado en la perspectiva del poder simbólico del Estado, el autor demuestra cómo los actores sociales que buscan los puestos de administración estatal internalizan conceptos culturales que orientan las prácticas tradicionales de la administración pública brasileña.

Finalmente, Liliana Raggio y Pablo Félix Martín, en un artículo escrito a dos voces, se preguntan "qué cambios se produjeron y cuáles han sido algunas constantes en la dinámica estatal entre la década del noventa y la actualidad, pasando por los años del kirchnerismo (2003-2015) y los de la gestión del macrismo (2015-2019) en los procesos de formulación y gestión de los programas públicos." (pp. 222, en este volumen) Para responder esta pregunta, recuperan sus propias experiencias de trabajo en el marco de dos programas específicos, reflexionando sobre lo que caracterizan como una doble perspectiva del actor/a y agente institucional: el Programa Materno Infantil y Nutrición, desarrollado durante los noventa del siglo XX, y el Programa Nacional de Educación Sexual Integral, llevado adelante entre los años 2009 y 2018. A partir de un recorrido por las principales características de estas experiencias estatales -a las que focalizan en la doble dimensión del Estado, en tanto producto y productor de las relaciones de poder que se ponen de manifiesto en cada momento histórico-, destacan la potencia que las políticas públicas adquieren a la hora de modelar los horizontes de sentido de una época.

\section{Q Referencias bibliográficas}

» Shore C. (2010). La antropología y el estudio de la la política pública: reflexiones sobre la "formulación de las políticas. Antipodas, 10, 21-49. 
